\title{
Recent advances in tailoring the aggregation of heavier alkaline earth metal halides, alkoxides and aryloxides from non-aqueous solvents $\uparrow$
}

\author{
Katharina M. Fromm* \\ Received 31st July 2006, Accepted 11th September 2006 \\ First published as an Advance Article on the web 22nd September 2006 \\ DOI: $10.1039 / \mathrm{b} 611042 \mathrm{~h}$
}

This overview on one of the subjects treated in our group deals with the synthesis and study of low-dimensional polymer and molecular solid state structures formed with alkaline earth metal ions in non-aqueous solvents. We have chosen several synthetic approaches in order to obtain such compounds. The first concept deals with the "cutting out" of structural fragments from a solid state structure of a binary compound, which will be explained with reference to $\mathrm{BaI}_{2}$. Depending on the size and concentration of oxygen donor ligands, used as chemical scissors on $\mathrm{BaI}_{2}$, three-, two-, one- and zero-dimensional derived adducts of $\mathrm{BaI}_{2}$ are obtained, comparable to a structural genealogy tree for $\mathrm{BaI}_{2}$. A second part deals with the supramolecular approach for the synthesis of low dimensional polymeric compounds based on alkaline earth metal iodides, obtained by the combination of metal ion coordination with hydrogen bonding between the cationic complexes and their anions. Certain circumstances allow rules to be established for the prediction of the dimensionality of a given compound, contributing to the fundamental problem of structure prediction in crystal engineering. A third section describes a synthetic approach for generating pure alkaline earth metal cage compounds as well as alkali and alkaline earth mixed metal clusters. A first step deals with different molecular solvated alkaline earth metal iodides which are investigated as a function of the ligand size in non-aqueous solvents. These are then reacted with some alkali metal compound in order to partially or totally eliminate alkali iodide and to form the targeted clusters. These unique structures of ligand stabilized metal halide, hydroxide and/or alkoxide and aryloxide aggregates are of interest as potential precursors for oxide materials and as catalysts. Approaches to two synthetic methods of the latter, sol-gel and (MO)CVD (metal-organic chemical vapour deposition), are investigated with some of our compounds. (D. C. Bradley, Chem. Rev., 1989, 89, 1317-22; K. G. Caulton and L. G. Hubert-Pfalzgraf, Chem. Rev., 1990, 90, 969-95; T. P. Hanusa, Coord. Chem. Rev., 2000, 210, 329-367; T. P. Hanusa, in Comprehensive Coordination Chemistry II, ed. J. A. McCleverty and T. J. Meyer, Elsevier, Amsterdam, 2004, vol. 3, 1-92). Finally, the physical properties of some of our compounds are described qualitatively in order to show the wide spectrum of possibilities and potential applications for chemistry in this field.

University of Basel, Department of Chemistry, Spitalstrasse 51, CH-4056, Basel.E-mail: katharina.fromm@unibas.ch; Fax: +4161267 1021; Tel: +41 612671004

$\dagger$ The HTML version of this article has been enhanced with colour images. \$ Address from 1st October 2006: Chemistry Department, University of Fribourg, Ch. du Musee 9, CH-1700 Fribourg, Switzerland. E-mail: katharina.fromm@unifr.ch.

\section{Introduction}

We became interested in the non-aqueous chemistry of alkaline earth metal elements for several reasons: i) the chemistry of alkaline earth metal compounds in water can best be described as ionic whereas not much was known about their behaviour

Katharina M. Fromm studied chemistry at the University of Karlsruhe, Germany, and the Ecole des Hautes Etudes des Industries Chimiques of Strasbourg (EHICS), France, where she received her degree in 1991. She did a PhD in metal-organic chemistry at the University of Karlsruhe until 1994, before starting her own research on alkaline earth metal chemistry during a postdoc at the University of Tübingen, Germany. After a postdoc in the group of Jean-Marie Lehn in Strasbourg, she continued her own work at the University of Geneva, Switzerland where she received her habilitation in 2002. She built up her group with an Emmy-Noether-Program II from the Deutsche Forschungsgemeinschaft, and a Swiss National Science Foundation research professorship at the Universities of Karlsruhe, Germany, and Basel, Switzerland, respectively, before accepting a chair at the University of Fribourg, Switzerland, as of October 1st 2006.

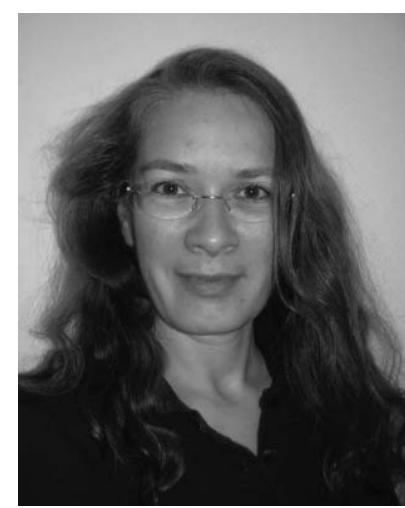

Katharina M. Fromm 
in more organic solvents except for the well-studied Grignard reagents and inverse crown chemistry; ${ }^{1}$ ii) alkaline earth metal clusters - in the sense of aggregates or cage compounds - were observed mainly as by-products in metallation reactions in organic chemistry which encouraged us to make such compounds on purpose; iii) we wanted to know whether there is an analogy in the clusters of Group 2 and transition metal clusters; iv) concerning the "covalent" polymers, the principle of cutting out structural fragments from a solid state structure with chemical scissors was to be tested; v) single source precursors for chemical vapour deposition or sol-gel techniques in the synthesis of oxide materials are scarce; vi) alkaline earth metal compounds were described as being catalysts for polymerisation reactions, but no structure of the involved compounds was known; and vii) we wanted to contribute to the problem of structure prediction in the case of supramolecular coordination polymers. Applications for such alkaline earth metal compounds can be found in many fields, such as in metallation reactions, as catalysts in organic chemistry, in biomineralization and biomimetics as far as biology is concerned, or as precursors for superconductors or other oxide materials required for physical applications. For the latter, thin films of such materials are currently the focus of research, and therefore we aimed at the synthesis of precursors for thin film synthesis methods such as the sol-gel or chemical vapour deposition (CVD) technique.

This article will review the alkaline earth metal ions project in our group, starting with the inorganic "covalent" polymers, followed by the supramolecular coordination polymers of alkaline earth metal ions, and finally a survey of our cluster compounds, before concluding about the properties and some potential applications. Our research focuses on the alkaline earth metal iodides because they are more soluble than the other halides in aprotic organic solvents. ${ }^{2}$

\section{Results and discussions}

\section{Inorganic "covalent" polymers}

This part of the project describes the principle of cutting out structural fragments from a three-dimensional compound, using chemical scissors and by maintaining parts of the initial structure. $^{3,4}$ In order to choose which "bonds" to "cut", these bonds need to be different to be selectively addressable, and the most obvious parameter to look at is thus the bond lengths. The starting material $\mathrm{BaI}_{2}$ possesses a $\mathrm{PbCl}_{2}$-type structure in the solid state, with the alkaline earth metal ion surrounded by nine iodide ions in form of a distorted, tri-capped trigonal prism (Fig. 1a). This leads to very different Ba-I distances, seven of which are comprised between 3.3 and $3.6 \AA$, and the other two are approximately $4.1 \AA$ long. The idea is to use O-donor ligands as chemical scissors in order to "cut" selectively the longest remaining $\mathrm{Ba}-\mathrm{I}$ bonds in the structure and to, successively, cut out structural fragments. With $\mathrm{H}_{2} \mathrm{O}$ acting as chemical scissor on $\mathrm{BaI}_{2}$, the three-dimensional compound $\left[\mathrm{BaI}_{2}\left(\mu_{2}-\mathrm{H}_{2} \mathrm{O}\right)_{2}\right]_{3 / \infty} 1$ can be isolated (Fig. 1b). Compared to $\mathrm{BaI}_{2}$, the longest $\mathrm{Ba}-\mathrm{I}$-contacts are cut, and the trigonal prism of iodide around the cation is maintained. The three capping anions are replaced by four $\mu_{2}-$ bridging water molecules. The remaining $\mathrm{Ba}-\mathrm{I}$ contacts compared to $\mathrm{BaI}_{2}$ are six of the shorter ones and are found between 3.3 and $3.6 \AA$. Upon substitution of one of the two bridging water molecules by a sterically more demanding oxygen donor ligand like acetone $\left(\mathrm{CH}_{3}\right)_{2} \mathrm{CO}$ to yield $\left[\mathrm{BaI}_{2}\left(\mu_{2}-\mathrm{H}_{2} \mathrm{O}\right)\left\{\left(\mathrm{CH}_{3}\right)_{2} \mathrm{CO}\right\}\right]_{2 / \infty}, \mathbf{2}$, a two-dimensional structure is obtained with the acetone ligand in a terminal position (Fig. 1c). The bulky $\mathrm{CH}_{3}$-groups allow separation of the layers from each other, and the trigonal prismatic arrangement of the six iodide ions around barium is maintained. ${ }^{3}$

Using THF as a sterically more demanding donor ligand, two derivatives of $\mathrm{BaI}_{2}$ can be obtained depending on the quantity of "chemical scissors". With three THF-molecules per $\mathrm{BaI}_{2}$, a onedimensional polymer $\left[\mathrm{BaI}_{2}(\mathrm{thf})_{3}\right]_{1 / \infty}, \mathbf{3}$, is obtained, in which only four Ba-I bonds are maintained (Fig. 1d). The other coordination sites on the cation are filled with the bulky THF-ligands to lead to the coordination number of seven for barium. Two more $\mathrm{Ba}-$ I bonds are cut upon the addition of more THF to yield the zero-dimensional $\left[\mathrm{BaI}_{2}(\mathrm{thf})_{5}\right], 4$, in the form of a pentagonal bipyramid with the anions in axial positions (Fig. 1e). The Ba-I bonds become shorter, as their number per cation as well as the coordination number of $\mathrm{Ba}$ decreases, to reach $3.374 \AA$, which is consistent if not shorter than the sum of the ionic Shannon radii. ${ }^{3}$

This "structural genealogy tree" for $\mathrm{BaI}_{2}$ could also be transferred to $\mathrm{SrI}_{2}$ and $\mathrm{Ba}(\mathrm{OTf})_{2}\left(\mathrm{OTf}=\mathrm{CF}_{3} \mathrm{SO}_{3}{ }^{-}\right){ }^{5}$ Whereas the structures for the corresponding $\mathrm{SrI}_{2}$-derivatives are similar to the $\mathrm{BaI}_{2}$-adducts, other structures are obtained for barium triflate. Using THF as scissor on this starting material leads to the one-dimensional THF-adduct of $\mathrm{Ba}(\mathrm{OTf})_{2}$, $\left[\left\{\left[\mathrm{Ba}(\mathrm{OTf})_{2}(\mathrm{thf})_{3}\right]_{2}\left[\mathrm{Ba}(\mathrm{OTf})_{2}(\text { thf })_{2}\right]\right\}_{1 / \infty}\right.$, 5. The asymmetric unit consists of two barium atoms $\mathrm{Ba} 1$ and $\mathrm{Ba} 2$ with a different coordination sphere each, two THF-molecules and six triflate ligands for $\mathrm{Ba} 1$, three THF-ligands and five triflate anions for $\mathrm{Ba} 2$. The eight oxygen atoms around $\mathrm{Ba} 1$ form a square antiprism. Four of the six triflate anions are $\mu_{3}$ - and two are $\mu_{2}$-bridging ligands, whereas the THF-molecules act as terminal ligands (Fig. 2). For $\mathrm{Ba} 2$, the coordination sphere is different with five triflate anions, four of them $\mu_{3}$-bridging and one $\mu_{2}$-bridging, and three terminal THF-ligands, the oxygen atoms also forming a distorted square antiprism around the barium cation. ${ }^{5}$

The crystal structure of $\mathrm{Ba}(\mathrm{OTf})_{2}$ is unknown, but IR-spectra indicate tridentate triflate ligands corresponding to a similar structure of the compound as for other $\mathrm{M}(\mathrm{OTf})_{2}$ compounds, $\mathrm{M}=$ $\mathrm{Ni}, \mathrm{Co}, \mathrm{Zn}, \mathrm{Cd}^{6}{ }^{\mathrm{M}}$ Many such triflates possess a layered, twodimensional structure. The one-dimensional compound $\mathbf{5}$ can therefore be understood as an excerpt of such a structure. Furthermore, the literature known complex $\left[\left\{\mathrm{Ba}(\mathrm{OTf})_{2}\right\}_{4}(\mathrm{py})_{14}\right] \cdot \mathrm{py}^{8}$ can be considered as an excerpt from $\mathbf{5}$, regarding the structural part containing barium cations and triflate anions, ${ }^{5}$ pyridine being a stronger chemical scissor than THF in this context.

We are now investigating other binary compounds of $\mathrm{M}^{2+}$ transition metals and lanthanides, in which very different bond lengths are observed to proceed similarly. This is of interest as such low-dimensional compounds possess an intrinsic anisotropy, which can be fundamental for the expression of their physical properties.

\section{Supramolecular inorganic polymers}

Here, we interest ourselves in the formation of different dimensional supramolecular arrays obtained by the combination of two binding modes, namely metal ion coordination, and 


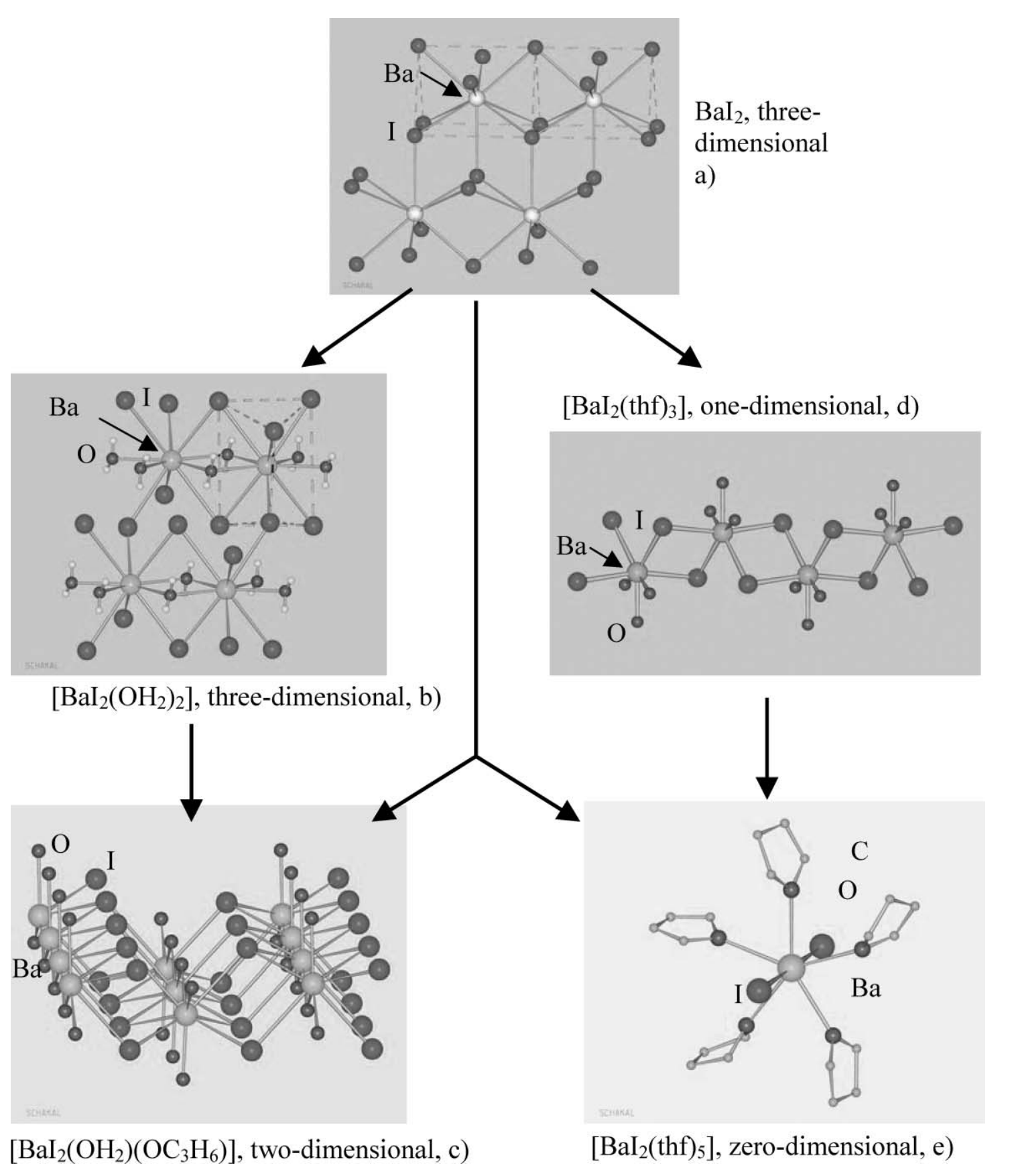

Fig. 1 Structural genealogy tree for $\mathrm{BaI}_{2}$ showing structures 1-4 in relation to $\mathrm{BaI}_{2}$.

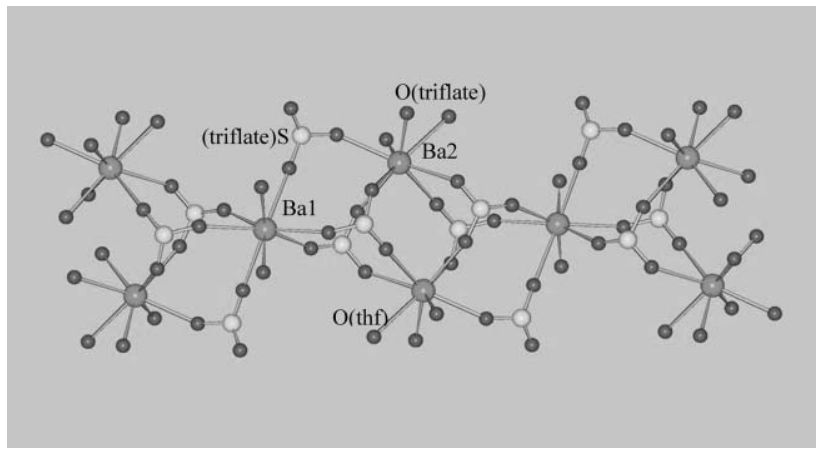

Fig. 2 Excerpt of the one-dimensional solid state structure of 5. hydrogen bonds. The aim of this project is to contribute to the field of structure prediction, or, at least, the prediction of the dimensionality of a compound in the solid state. Cationic complexes of alkaline earth metal ions with at least one water molecule in the coordination sphere of the cation, use this/these water ligand/s as hydrogen bonding partner/s for spherical anions such as iodide. ${ }^{8-12}$ Preliminary experiments led to the conclusion, that it is only possible to predict interactions between complex cations, the counter ions and solvent molecules under very specific conditions. Thus, the compound trans- $\left[\mathrm{Ca}(\mathrm{L})_{4}\left(\mathrm{H}_{2} \mathrm{O}\right)_{2}\right] \mathrm{I}_{2}$ does not form similar structures even when ligands $\mathrm{L}$ are of similar size and donor atoms are used, which are not involved in $\mathrm{H}$-bonding. ${ }^{8}$ Thus, the compound in which $\mathrm{L}=\mathrm{THF}, \mathbf{6}$, forms a two-dimensional 
network via hydrogen bonds, whereas for $\mathrm{L}=$ ethyl acetate $\left(\mathrm{CH}_{3} \mathrm{COOC}_{2} \mathrm{H}_{5}\right), 7$, one-dimensional chains are observed (Fig. 3a and $b$ ).

a)

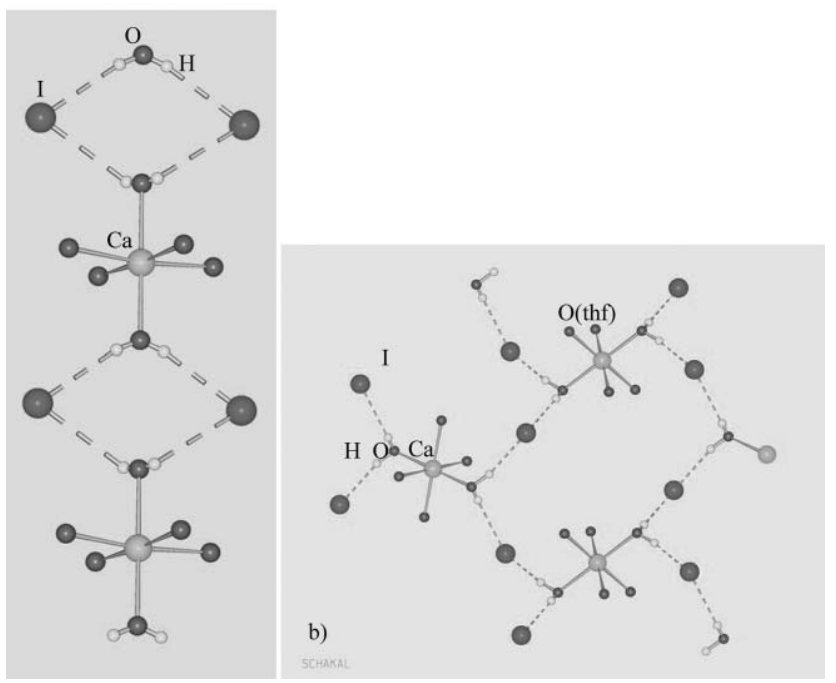

Fig. 3 Comparison of the structures $\left[\mathrm{Ca}(\mathrm{L})_{4}\left(\mathrm{H}_{2} \mathrm{O}\right)_{2}\right] \mathrm{I}_{2}$ with $\mathrm{L}=\mathrm{THF}$ and ethyl acetate.

This, together with other results, ${ }^{9}$ lead us to fix the conditions to predict at least the dimensionality of a compound: i) the cations form complexes with a $2+$ charge having inert polyether ligands and $\mathrm{H}$-bonding water molecules, ii) the counterions $\mathrm{X}^{-}$are the only H-bond acceptors, iii) the water ligands, if more than one, are arranged in vicinal positions, iv) only the water molecules are involved in hydrogen bonding, and v) each hydrogen of the water molecules forms a single hydrogen bond to $\mathrm{X}^{-}$, excluding the fact that two hydrogen atoms of the same water molecule bind to the same anion. ${ }^{10}$ The only variable is therefore the bridging functionality of iodide and the number of water ligands per cationic complex. Under these conditions, the number of water molecules coordinated to the alkaline earth metal cation, directs the dimensionality of the final compound. A compound with one water molecule, like $\left[\mathrm{Ba}(\text { triglyme })_{2}\left(\mathrm{H}_{2} \mathrm{O}\right)\right] \mathrm{I}_{2}, 8$, has a zero-dimensional structure, one with two water molecules forms a one-dimensional chain, i.e. $\left[\mathrm{Ca}(\text { diglyme })_{2}\left(\mathrm{H}_{2} \mathrm{O}\right)_{2}\right] \mathrm{I}_{2}, 9$, three water molecules present will give a two-dimensional doublelayer as in $\left[\mathrm{Ba}(\text { diglyme })_{2}\left(\mathrm{H}_{2} \mathrm{O}\right)_{3}\right] \mathrm{I}_{2}, \mathbf{1 0}$, and four water molecules bonded to the cation will lead to a three-dimensional compound, i.e. $\left[\mathrm{Ca}(\right.$ triglyme $\left.)\left(\mathrm{H}_{2} \mathrm{O}\right)_{4}\right] \mathrm{I}_{2}$ or $\left[\mathrm{Ca}(\mathrm{dme})_{2}\left(\mathrm{H}_{2} \mathrm{O}\right)_{4}\right] \mathrm{I}_{2}, 11$ and $\mathbf{1 2}$, respectively (Fig. 4a, b, c and d, for 8, 9, 10 and 11 respectively). ${ }^{11}$ Compounds $9 \mathrm{a}$ and 11a, isostructural with 9 and 11, respectively, have been obtained with $\mathrm{Sr}$ instead of $\mathrm{Ca} .{ }^{12}$

In the case where four water ligands are bonded to the alkaline earth metal cation, even the compound in which the anions are directly linked to the cation can form a three-dimensional structure, as has been shown for $\left[\mathrm{Ba}(\mathrm{OH}) \mathrm{I}\left(\mathrm{H}_{2} \mathrm{O}\right)_{4}\right], \mathbf{1 3}^{11}$

We are now investigating how this concept can be generalised to other metal ions, ligands and anions in order to contribute to this important field of fundamental research.

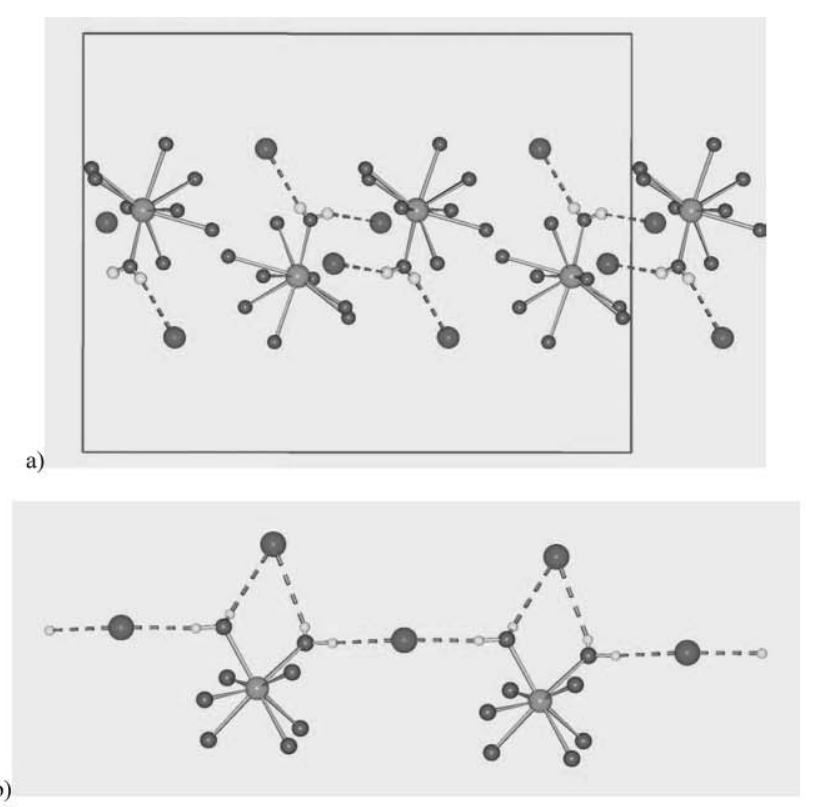

b)
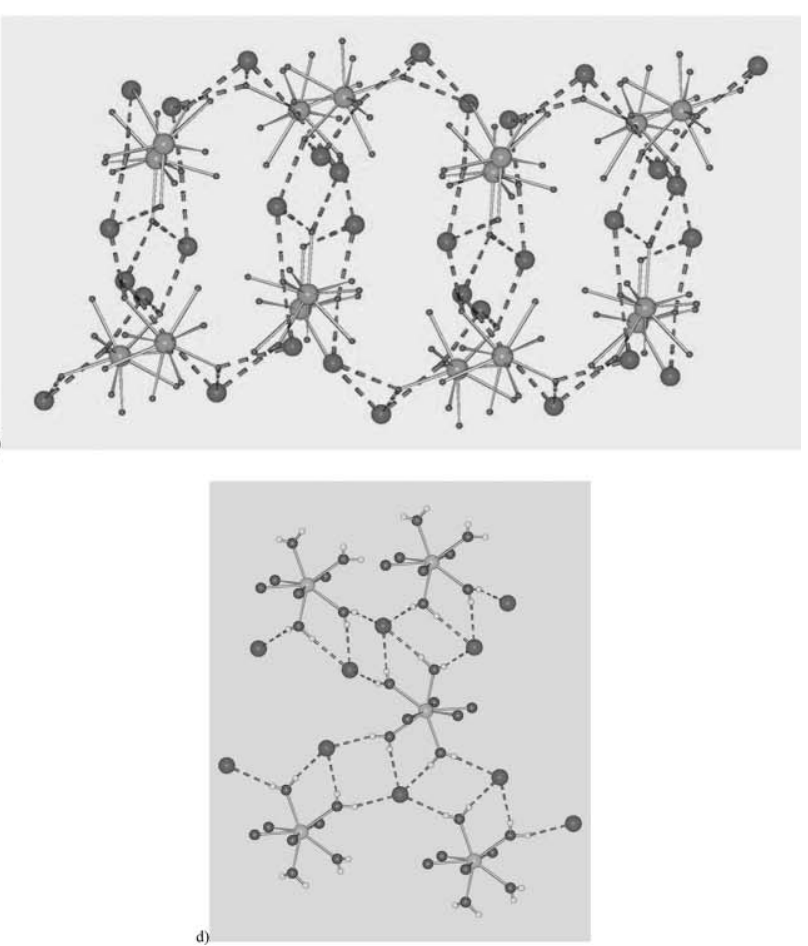

Fig. 4 Increasing dimensionality with increasing numbers of $\mathrm{H}_{2} \mathrm{O}$-molecules coordinated to the alkaline earth metal ions: a) [Ba(triglyme $\left.)_{2}\left(\mathrm{H}_{2} \mathrm{O}\right)\right] \mathrm{I}_{2} ;$ b) $\left[\mathrm{Ca}(\text { diglyme })_{2}\left(\mathrm{H}_{2} \mathrm{O}\right)_{2}\right] \mathrm{I}_{2} ;$ c) $\left[\mathrm{Ba}(\text { diglyme })_{2}\left(\mathrm{H}_{2} \mathrm{O}\right)_{3}\right] \mathrm{I}_{2}$; d) $\left[\mathrm{Ca}(\mathrm{dme})_{2}\left(\mathrm{H}_{2} \mathrm{O}\right)_{4}\right] \mathrm{I}_{2}$.

\section{Clusters of alkali and alkaline earth metals}

As an analogy to transition metal clusters, the following general reaction scheme (1) for obtaining alkaline earth metal clusters was applied:

$$
n \mathrm{MX}_{2}+n \mathrm{AOR} \underset{+ \text { Ligand L }}{\stackrel{-\left\{[\mathrm{AX}] \eta_{n}\right.}{\longrightarrow}}\left[(\mathrm{L})_{m} \mathrm{M}_{n} \mathrm{X}_{n}(\mathrm{OR})_{n}\right]
$$


with $\mathrm{MX}_{2}$ being an alkaline earth metal iodide, AOR being either $\mathrm{LiOH}, \mathrm{LiO}^{\prime} \mathrm{Bu}, \mathrm{NaO}^{t} \mathrm{Bu}$ or $\mathrm{LiOPh}$, and $\mathrm{L}$ an oxygen donor ligand like THF or some polyether.

Our interest focused first on the potential starting compounds of the type $\left[\mathrm{MI}_{2}(\mathrm{~L})_{x}\right]$, as such adducts are formed in the cases where $\mathrm{L}$ is also used as non-aqueous, aprotic solvent. In water as solvent, ion separation takes place and a typical ionic behaviour of the alkaline earth halides is observed. In organic solvents such as THF or polyethers ( $\mathrm{L}=\mathrm{DME}$, diglyme), the $\mathrm{M}-\mathrm{I}$ contacts remain mostly intact, and the alkaline earth halide is dissolved forming adducts $\left[\mathrm{MI}_{2}(\mathrm{~L})_{x}\right]$ where $x$ depends on the size of the cation and the size and flexibility of the ligand L, similar to the ones observed for lanthanide cations, their coordination chemistry being very similar. ${ }^{13}$ As described in the first part of this paper, the zero-dimensional structures $\left[\mathrm{MI}_{2}(\text { thf })_{5}\right], \mathrm{M}=\mathrm{Ba}$ and $\mathrm{Sr}, 4$ and $\mathbf{1 4}$ respectively, were found to have a trans arrangement of the anions in a distorted pentagonal bipyramidal arrangement of ligands around the cation, as expected from the VSEPR model, due to maximum repulsion of the negative charges. This is also observed for $\left[\mathrm{CaI}_{2}(\mathrm{thf})_{4}\right], \mathbf{1 5}$, a literature known compound which we also crystallised, but in a different space group. ${ }^{14,15}$ As the Ca-cation is smaller than $\mathrm{Sr}$ and $\mathrm{Ba}$, the coordination number is reduced from seven to six (Fig. 5). ${ }^{14,16,17}$

a)

b)
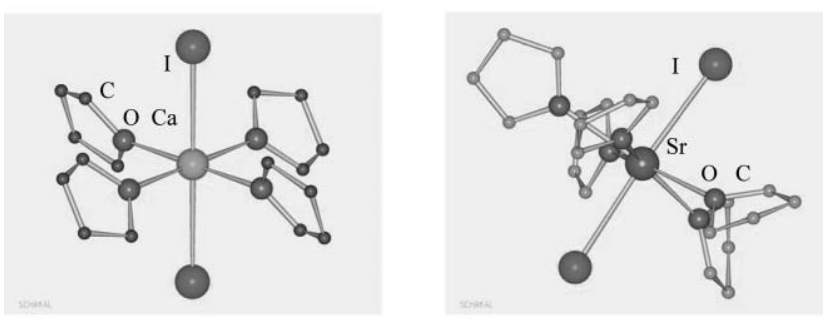

c)

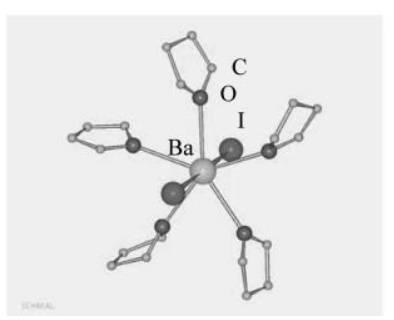

Fig. 5 Molecular structures of $\left[\mathrm{MI}_{2}(\text { thf })_{x}\right]$ for a) $\mathrm{M}=\mathrm{Ca}, x=4$; b) $\mathrm{M}=$ Sr, $x=5$; c) $\mathrm{M}=\mathrm{Ba}, x=5$.

When $\mathrm{SrI}_{2}$ is dissolved and re-crystallised from freshly dried and distilled diglyme $\left(\mathrm{CH}_{3} \mathrm{OC}_{2} \mathrm{H}_{4} \mathrm{OC}_{2} \mathrm{H}_{4} \mathrm{OCH}_{3}\right)$, only the compound cis-[ $\left.\mathrm{SrI}_{2}(\text { diglyme })_{2}\right], \mathbf{1 6}$, is obtained. ${ }^{16-18}$ Two independent molecules both consist of a strontium cation to which two diglyme ligands and two anions are directly linked (Fig. 6). In contrast to 14, the I-Sr-I angles are, at $c a .91 .5^{\circ}$, much smaller and close to a right angle. Together with the oxygen donor ligands, the coordination sphere of the cation can now be described as severely distorted square antiprismatic, with a common coordination number of eight for the Sr-cation. The most intriguing fact about this structure is the fact that both anions occupy vicinal positions. In general, to obtain such structures with the anions in cis-position, a sterically important ligand, which shields one
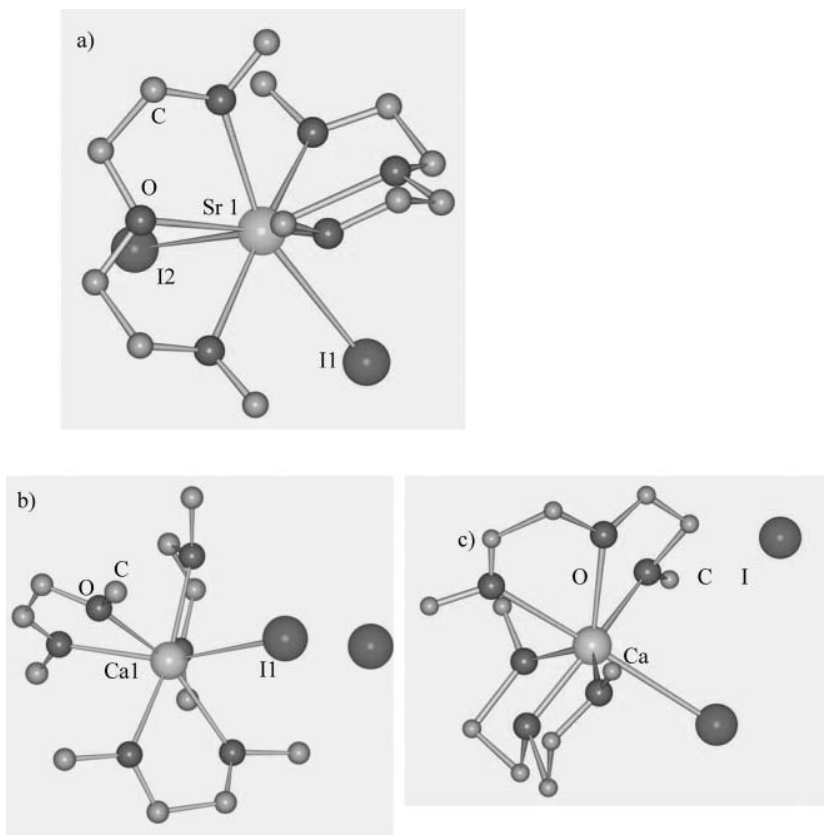

Fig. 6 Survey of polar alkaline earth metal iodides: a) cis-[Sr(diglyme $\left.)_{2} \mathrm{I}_{2}\right]$; b) $\left[\mathrm{CaI}(\text { dme })_{3}\right] \mathrm{I}$; c) $\left[\mathrm{CaI}(\text { diglyme })_{2}\right] \mathrm{I}$.

side of the cation, such as slightly too small crown ethers, is required, and even then, the $\mathrm{X}-\mathrm{M}-\mathrm{X}$ angles are usually much larger, and the $\mathrm{M}-\mathrm{X}$ bonds are longer than in $\mathbf{1 6}$, the anions being involved in $\mathrm{H}$-bonding to build up a polymer structure. $\mathbf{1 6}$ is therefore the first example of a polar molecular alkaline earth metal iodide precursor. The strongly bent $\mathrm{I}-\mathrm{Sr}-\mathrm{I}$ feature in this structure is reminiscent of the heavier alkaline earth metal halides, $\mathrm{SrI}_{2}$ and $\mathrm{BaI}_{2}$, in the gas phase. Indeed, experimental as well as theoretical data show bent structures for these molecules in the gas phase. ${ }^{14,19}$ So, $\mathbf{1 6}$ could be compared to a gas phase species stabilised by oxygen donor ligands. The bent structure resembles also the cyclopentadienyl derivatives of the alkaline earth metals with bent structures as well. However, in the solid state, they form polymers via contacts to neighbouring units.

$\left[\mathrm{CaI}(\mathrm{dme})_{3}\right] \mathrm{I} 17$, was obtained when crystallizing $\mathrm{CaI}_{2}$ from freshly dried and distilled DME. ${ }^{18} 17$ is built up from two independent cationic molecules $\mathrm{A}$ and $\mathrm{B}$ per asymmetric unit, each consisting of a calcium cation, $\mathrm{Ca} 1$ and $\mathrm{Ca} 2$, to which one iodide and three DME-ligands are bonded, and two separate iodides as counter ions (Fig. 6). The coordination geometry can roughly be described as a distorted pentagonal bipyramid with one iodide and one of the oxygen atoms in axial positions. A similar compound can be obtained by replacing the three DME-ligands of $\mathbf{1 7}$ by two, larger diglyme molecules to give [CaI(diglyme $\left.)_{2}\right] \mathrm{I}$, 18 (Fig. 6). The number of oxygen atoms remains identical, and their arrangement around the cation is very similar to $\mathbf{1 7}$. We have shown before (compounds $\mathbf{1 0}$ and 11) that small polyether molecules (such as DME) can easily be replaced by larger ones (diglyme or triglyme for instance) as long as the number of oxygen atoms remains constant, without significant changes in the structure. The cations $\left[\mathrm{CaI}(\mathrm{dme})_{3}\right]^{+}$and $\left[\mathrm{CaI}(\text { diglyme })_{2}\right]^{+}$of $\mathbf{1 7}$ and 18, respectively, possess a strong dipole moment along the $\mathrm{Ca}-\mathrm{I}$ bond vector. Such polar species are scarce: in the literature, only one example with calcium and iodide was described so far 
to our knowledge, $\left[\mathrm{CaI}(\mathrm{thf})_{5}\right]^{+}$, in which the cation possesses a coordination number of six, the counter ion being an extremely bulky phosphonium diylide. ${ }^{20}$ Given these results for alkaline earth metal iodides in aprotic solvents, we rediscussed the $\mathrm{M}-\mathrm{I}$ bond as partially covalent in behaviour. ${ }^{17}$ This has been confirmed in our findings for cluster compounds of alkaline earth metal ions, as will be shown next.

Among the presented starting materials, the THF-adducts turned out to be most useful in obtaining cluster compounds following the reaction scheme (1), as will be presented in the next paragraphs. ${ }^{14,16,17}$

Using $\mathrm{CaI}_{2}$ under the conditions given in reaction scheme (1), we were able to isolate the largest Ca-cluster so far, $\operatorname{Li}\left[\mathrm{Ca}_{7} \mathrm{I}_{6}\left(\mu_{3}\right.\right.$ $\left.\mathrm{OH})_{8}(\text { thf })_{12}\right]_{2}\left(\mu_{2}-\mathrm{I}\right)(\mathrm{THF})_{\mathrm{n}}, 19$, with a unique structure of two double-hetero-cubanes linked together via hydrogen bonds to a central iodide, yielding a dumbbell-shaped cluster of fourteen calcium ions (Fig. 7). ${ }^{21}$ One $\mathrm{Ca}_{7}$-unit consists of two Ca-fused metal ion tetrahedra with all triangular faces bridged with $\mathrm{OH}$ groups. The central cation has a coordination sphere of six $\mathrm{OH}-$ groups in a nearly octahedral environment. Two THF-ligands and one iodide are terminally bonded to the other six Ca-cations, which have their quasi octahedral coordination sphere completed by three bridging $\mathrm{OH}$-groups. One of these $\mathrm{OH}$-groups $\mathrm{H}$-binds to an iodide in order to bridge to the second $\mathrm{Ca}_{7}$-cluster unit, a mirror image of the first, and yields the overall dumbbell-shape of the aggregate. A Li-cation, coordinated by four THF-ligands, acts as counter-ion to the negatively charged cluster 19.

a)

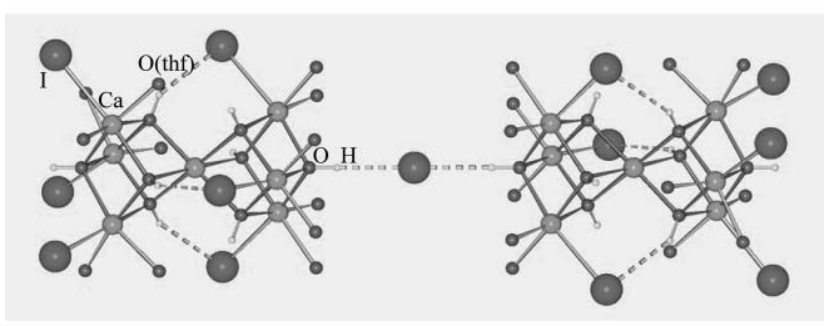

b)

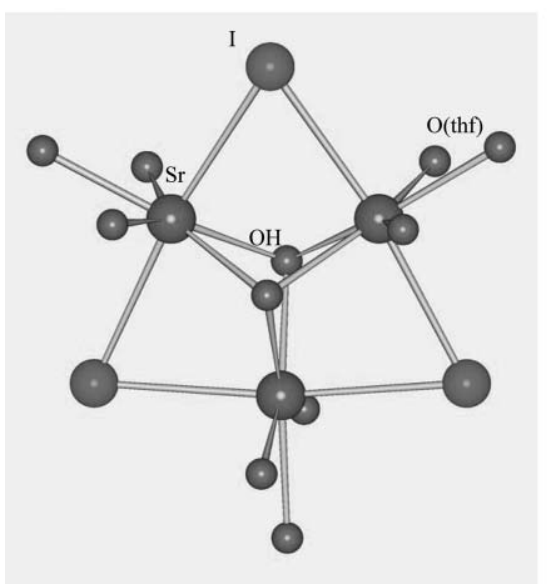

Fig. 7 Examples of clusters obtained with $\mathrm{LiOH}$ as reagent with $50 \%$ of iodide abstraction: a) a $\mathrm{Ca}_{14}$-cluster; b) the smallest building block of polyhedral aggregates, the $\mathrm{Sr}_{3}$-cluster.
When $\mathrm{SrI}_{2}$ is used as starting material in a reaction scheme (1), $\left[\mathrm{Sr}_{3} \mathrm{I}_{3}\left(\mu_{3}-\mathrm{OH}\right)_{2}(\text { thf })_{9}\right] \mathrm{I}, \mathbf{2 0}$, is obtained (Fig. 7b). ${ }^{14}$ The three Sr-ions are arranged in a perfect triangle, its edges being bridged by iodide in the same plane, and by two $\mu_{3}$-bridging $\mathrm{OH}$-groups, one above, the second below the plane spanned by the cations. Each Sr-cation carries furthermore three THF-ligands to complete its coordination sphere, a distorted pentagonal bipyramid. It is interesting how the $\mathrm{I}-\mathrm{Sr}-\mathrm{I}$ angle varies from $\left[\mathrm{SrI}_{2}(\mathrm{thf})_{5}\right]$, 14, with ca. $176^{\circ}$ to $172^{\circ}$ in $\mathbf{2 0}$. This triangular arrangement seems to be a fundamental unit for the construction of higher aggregates, since most of the alkaline earth metal clusters form polyhedra or sheet structures in which triangles of alkali metal ions are fused together.

These two purely alkaline earth metal clusters $\mathbf{1 9}$ and $\mathbf{2 0}$ are not volatile, and can thus not be used as CVD (chemical vapor deposition) precursors. However, they form extremely stable sols in THF upon hydrolysis with, in the case of the calcium compound, a particle size of $c a .1000 \mathrm{~nm}$ and a particle composition of $\mathrm{Ca}(\mathrm{OH})_{2}\left(\mathrm{H}_{2} \mathrm{O}\right)_{n}$ which can be used to synthesise thin films of halide-free $\mathrm{CaO}^{14}$

In order to introduce volatility, we aimed to replace $\mathrm{LiOH}$ by $\mathrm{LiO}^{t} \mathrm{Bu}$ which is for itself volatile. ${ }^{14,22,23}$ Under the above reaction conditions (eqn (1)) and with $\mathrm{CaI}_{2}$ as starting material in THF, we were for the first time able to isolate not only the alkaline earth metal compound, but also the lithium derivative in the form of a pure lithium cluster $\left[\mathrm{Li}_{4}\left(\mu_{3}-\mathrm{O}^{t} \mathrm{Bu}\right)_{3}(\text { thf })_{4} \mathrm{I}\right] 21$ (Fig. 8). ${ }^{22}$ As can be seen from its composition, iodide has been partially stripped off the alkaline earth starting product, and so there must also be a new calcium compound in the reaction mixture. The latter could be crystallized from a DME/THF mixture, and consists of $\left[\mathrm{ICa}\left(\mathrm{O}^{t} \mathrm{Bu}\right)_{4}(\mathrm{Li}\{\mathrm{thf}\})_{4}(\mathrm{OH})\right], 22$, in which a calcium cation is surrounded by an iodide and four $\mathrm{O}^{t} \mathrm{Bu}$-groups (Fig. 9a). ${ }^{22}$ Four $[\mathrm{Li}(\text { thf })]^{+}$-units are linked to the $\mathrm{O}^{t} \mathrm{Bu}$-groups as well, the oxygen and lithium atoms forming a distorted square anti-prism. The open square face formed by the alkali metal ions is bridged by an $\mathrm{OH}$-group. The whole cluster has a spherical overall shape with mainly organic, apolar ligands pointing to the outside and shielding the cluster core. In analogy, the compounds

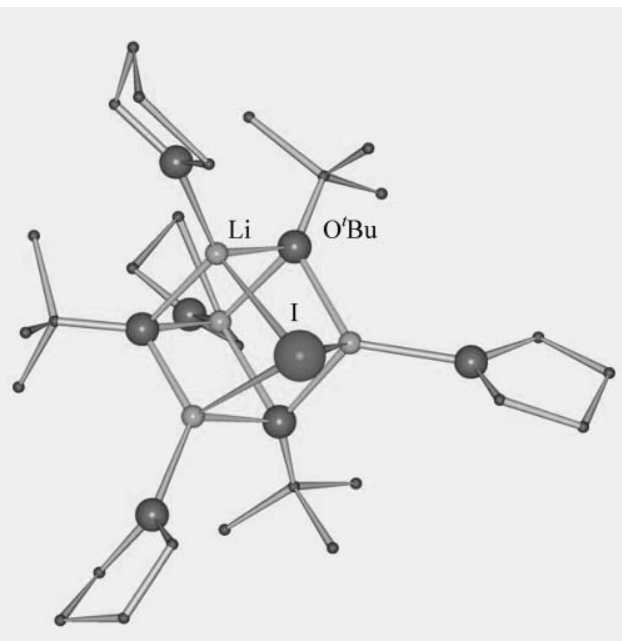

Fig. 8 The lithium cluster obtained as by-product during reactions of $\mathrm{MI}_{2}$ with $\mathrm{LiO}^{t} \mathrm{Bu}$. 


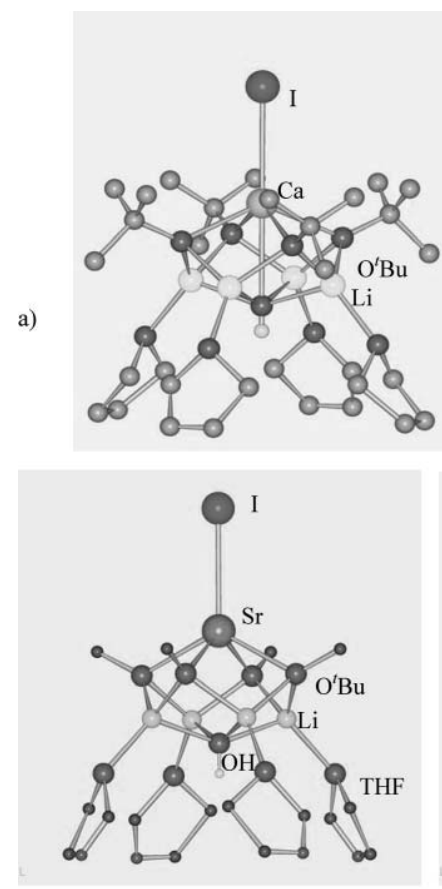

b)

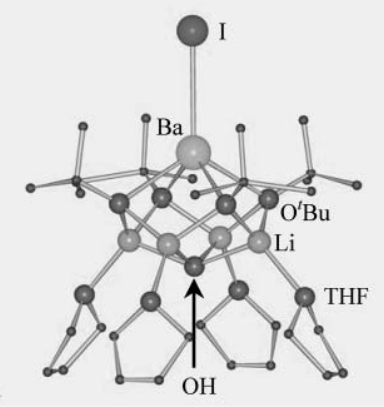

c)

Fig. 9 The series of volatile clusters $\left[\mathrm{IM}\left(\mathrm{O}^{t} \mathrm{Bu}\right)_{4}\{\mathrm{Li}(\mathrm{thf})\}_{4}(\mathrm{OH})\right]$ with $50 \%$ of iodide abstraction: a) $\mathrm{M}=\mathrm{Ca}$; b) $\mathrm{M}=\mathrm{Sr}$; c) $\mathrm{M}=\mathrm{Ba}$.

$\left[\mathrm{IM}\left(\mathrm{O}^{t} \mathrm{Bu}\right)_{4}\{\mathrm{Li}(\mathrm{thf})\}_{4}(\mathrm{OH})\right], \mathrm{M}=\mathrm{Sr}(\mathbf{2 3}),{ }^{14} \mathrm{Ba}(\mathbf{2 4}),{ }^{24}$ were isolated (Fig. 9b and c).

Comparing the structures of the three related compounds $\mathbf{2 2}$, 23, 24, it can be seen that the cluster core is more and more flattened the smaller the cation, and, vice versa, the $\mathrm{M}-\mathrm{OH}$ bond gets longer with increasing cation size. For compound 24, solution and solid state analysis were found to be congruent as far as ${ }^{6} \mathrm{Li}$ and ${ }^{13} \mathrm{C}$ NMR are concerned. The ${ }^{1} \mathrm{H}-\mathrm{NMR}$ of a solution of $\mathbf{2 4}$ in $\mathrm{d}_{8}$-THF shows a temperature dependency of the signal for the $\mathrm{OH}$-proton, indicating interactions of a $\mathrm{H}$-bonding nature in the cavity formed by the THF-molecules of the cluster. 24 also turns out to be volatile, and deposition tests were carried out. Partially crystalline product was deposited on $\mathrm{SrTiO}_{3}$, and after thermal treatment at $600{ }^{\circ} \mathrm{C}$, halide-free $\mathrm{BaO}$ is formed on the surface, as identified by Auger electron spectroscopy. As alkaline earth metal oxides are often ingredients for high temperature superconductors, compounds 22, 23 and $\mathbf{2 4}$ could possibly be applicable in the generation of halide free, quantitatively deposited oxides.

Up to now, reacting these species with $\mathrm{LiOR}, \mathrm{R}=\mathrm{H},{ }^{t} \mathrm{Bu}$, yielded homo- ${ }^{14,21,25}$ and heterometallic ${ }^{14,21,25}$ cage compounds in which $50 \%$ of the initial iodide ligands was substituted by OR, whereas the other half remained linked to the cations in the newly formed cage compound. Even with excess LiOR, R = $\mathrm{H},{ }^{t} \mathrm{Bu}$, we were unable to take off more than $50 \%$ of the initial iodide under the commonly used reaction conditions. When six equivalents of $\mathrm{SrI}_{2}$ are reacted with nine equivalents of $\mathrm{NaO}^{t} \mathrm{Bu}$ in a mixture of THF and hexanes in the presence of $\mathrm{PhN}(\mathrm{H}) \mathrm{Li}$, the monocrystalline compound $\left[\mathrm{Li}(\mathrm{thf})_{4}\right]^{+}\left[\left\{\mathrm{Sr}_{6}(\mathrm{O})\left(\mu_{3^{-}}\right.\right.\right.$ $\left.\left.\mathrm{I})(\mathrm{I})_{2}\left(\mathrm{O}^{t} \mathrm{Bu}\right)_{7}(\mathrm{thf})_{3}\right\}_{2}(\mu-\mathrm{I})\right]^{-}(\mathrm{THF})_{n}, \mathbf{2 5}(n=2$ or 3$)$, is obtained (Fig. 10) ${ }^{26}$ One cluster anion is formed of a centro-symmetric $\mathrm{Sr}_{12}{ }^{-}$ cluster consisting of two $\mathrm{Sr}_{6}$-units linked via iodide. Each $\mathrm{Sr}_{6}$-unit is a distorted octahedron of Sr-ions at the center of which an oxo-

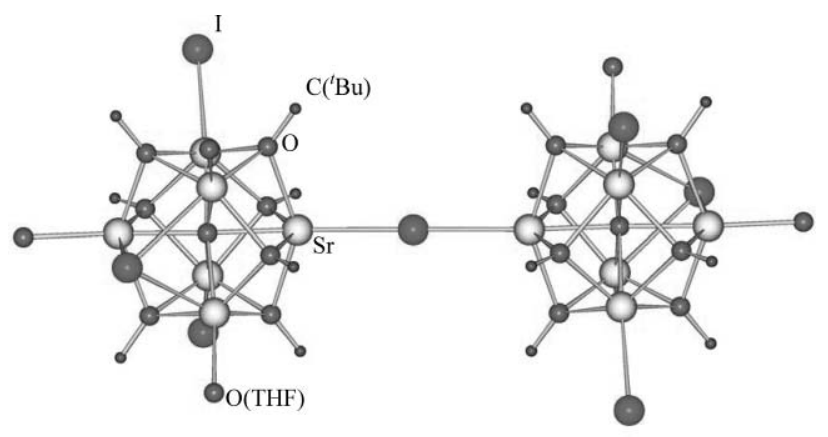

Fig. $10 \mathrm{The} \mathrm{Sr}_{12}$-cluster obtained upon $75 \%$ iodide abstraction with $\mathrm{NaO}^{t} \mathrm{Bu}$.

anion is found. Seven of the triangular faces of the octahedron are $\mu_{3}$-bridged with $\mathrm{O}^{\prime} \mathrm{Bu}$-anions, the eighth face is capped by iodide. The so far mentioned $\mathrm{Sr}-, \mathrm{O}^{t} \mathrm{Bu}-$ and I-ions span the corners of an irregular rhombic dodecahedron with the oxo-anion approximately in the center of the polyhedron. An alternative description is the oxo-centered, all-faces-capped $\mathrm{Sr}_{6}$-octahedron (Fig. 10). Three of the six Sr-ions carry terminal THF-ligands, two others have terminal iodide anions, and the last $\mathrm{Sr}$-ion is linked to the bridging anion. Thus, the iodide anions in $\mathbf{2 5}$ adopt three different coordination functions: terminal, or bridging between two or three Sr-cations. The overall dumbbell shape of this cluster is reminiscent of $\mathbf{1 9}$, however, the type of force holding the two equivalent halves of the clusters together is different: H-bonds in 19, and ionic bonds in $\mathbf{2 5}$. Thus, the use of a strongly basic mixture of $\mathrm{NaO}^{t} \mathrm{Bu}$ and $\mathrm{PhN}(\mathrm{H}) \mathrm{Li}$ is more efficient than $\mathrm{LiO}^{t} \mathrm{Bu}$ or $\mathrm{NaO}^{t} \mathrm{Bu}$ alone, and abstracts more than one iodide off each initial $\left[\mathrm{SrI}_{2}(\mathrm{thf})_{5}\right]$-unit. The substitution reaction however is not complete with respect to iodide, even if an excess of reagent is used. Also, none of the mixed alkali species described by Mulvey et al. have been observed ${ }^{27}$ So, for the first time, we were able to replace $c a .75 \%$ of the initial iodide by $\mathrm{O}^{t} \mathrm{Bu}$-groups, thus leading to the new type of aggregate found in $\mathbf{2 5}$.

Working under extremely dry and inert conditions, the reaction of $\mathrm{CaI}_{2}$ in THF with an excess of a $1 \mathrm{M}$ LiOPh-solution in THF yields crystals of $\left[\mathrm{CaLi}_{6}\left(\mu_{3}-\mathrm{OPh}\right)_{8}(\text { thf })_{6}\right], \mathbf{2 6} .^{28}$ The structure consists of two $\mathrm{CaLi}_{3}$-tetrahedra linked via the Ca-vertex (Fig. 11).

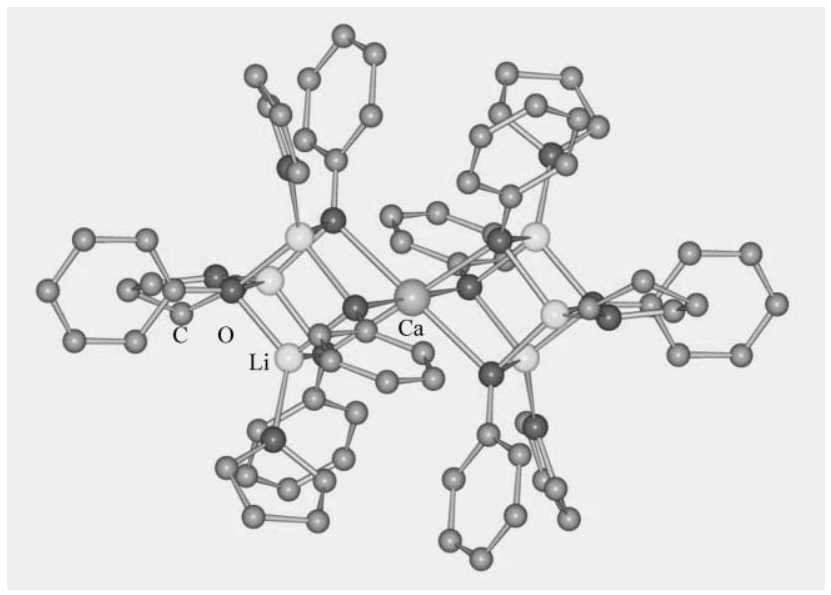

Fig. 11 The mixed metal $\left[\mathrm{CaLi}_{6}(\mathrm{OPh})_{8}(\text { thf })_{6}\right]$-cluster obtained upon total iodide abstraction with $\mathrm{LiOPh}$. 
All triangular faces of these two tetrahedra are $\mu_{3}$-bridged by phenolate groups. The structure can therefore alternatively be described as two vertex-sharing $\mathrm{CaLi}_{3} \mathrm{O}_{4}$-hetero-cubanes. The central calcium cation possesses six $\mathrm{O}^{t} \mathrm{Bu}$-neighbors, whereas each lithium ion is connected to three $\mathrm{O}^{t} \mathrm{Bu}$-anions and one terminal THF-ligand. 26 turns out to be sensitive to traces of air and humidity, and reacts easily with DME to yield $\left[\mathrm{Ca}_{2}(\mathrm{dme})_{2}(\mu-\right.$ $\left.\mathrm{OPh})_{6}\{\mathrm{Li}(\mathrm{dme})\}_{2}\right], 27{ }^{28}$ This cluster consists of a bent chain arrangement of $\mathrm{Li}-\mathrm{Ca}-\mathrm{Ca}-\mathrm{Li}$ in which the metal ions are pairwise bridged by two phenolate groups each (Fig. 12). The structure of $\mathbf{2 7}$ can also be described as a chain of two $\mathrm{LiO}_{2} \mathrm{Ca}$-rhombi, linked to a $\mathrm{CaO}_{2} \mathrm{Ca}$-rhombus via one Ca-cation. $\mathbf{2 6}$ and $\mathbf{2 7}$ differ in stoichiometry and structure, the only difference in the synthesis is however the use of solvent. We were thus interested in studying a possible transformation of $\mathbf{2 6}$ into $\mathbf{2 7}$ in solution. A series of ${ }^{7} \mathrm{Li}-\mathrm{NMR}$ spectra were taken in $\mathrm{d}^{8}$-THF and DME: Pure LiOPh gives a sharp signal at $0.82 \mathrm{ppm}$ in $\mathrm{d}^{8}-\mathrm{THF}$, and at $0.98 \mathrm{ppm}$ in DME. Crystals of $\mathbf{2 6}$ dissolved in $\mathrm{d}^{8}$-THF give two signals, a major peak at $0.79 \mathrm{ppm}$, and a smaller peak at $1.07 \mathrm{ppm}$, the latter representing $c a .10 \%$ of the large one. The spectrum of $\mathbf{2 6}$ could be interpreted as spontaneous decomposition of $\mathbf{2 6}$ in solution into the THF-analogue of 27, 27a, but with THF-ligands instead of DME, and LiOPh, following the reaction scheme below, eqn (2).

$$
2\left[\mathrm{CaLi}_{6}\left(\mu_{3}-\mathrm{OPh}\right)_{8}(\mathrm{thf})_{6}\right] \rightarrow\left[\mathrm{Ca}_{2} \mathrm{Li}_{2}(\mu-\mathrm{OPh})_{6}(\text { thf })_{x}\right]+10 \mathrm{LiOPh}
$$

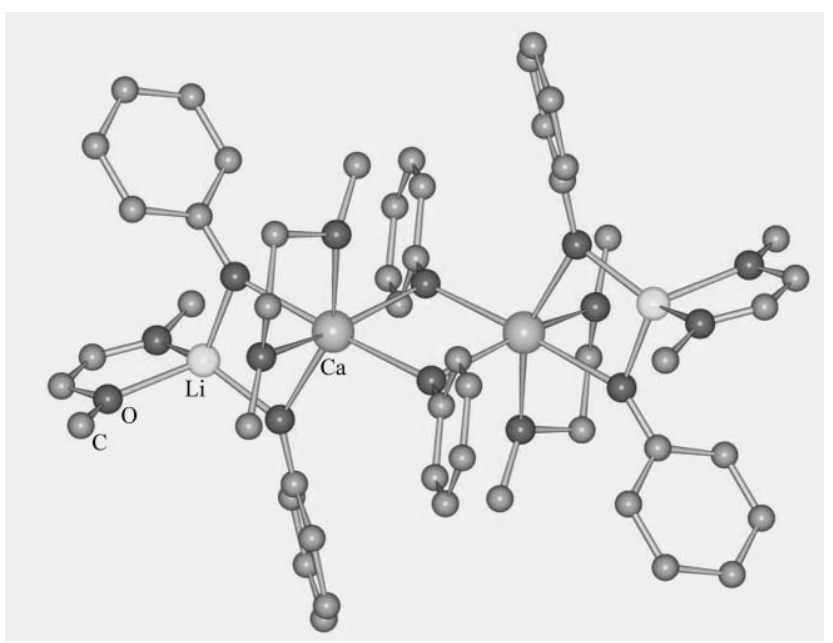

Fig. 12 The mixed metal $\left[\mathrm{Ca}_{2} \mathrm{Li}_{2}(\mathrm{OPh})_{6}(\mathrm{dme})_{4}\right]$-cluster obtained from DME.

This is in principle possible as it was shown that two THFligands in other solvate adducts such as $\left[\mathrm{CaI}_{2}(\mathrm{thf})_{4}\right]$ can be replaced by one bidentate DME molecule, ${ }^{8,9}$ and would explain the 1 : 10 relation in the NMR-signals for the two species. The species 27a, however, has so far not been isolated in the solid state. Crystals of 27 in $\mathrm{d}^{10}$-DME give one relatively sharp peak at $1.01 \mathrm{ppm}$, which is close in shift to the small peak obtained in the spectrum of 26. Such a cluster breakdown upon addition of a bidentate ligand as compared to a monodentate ligand is also observed for transition metal cluster compounds, i.e. $\left[\mathrm{Cr}_{2}(\mathrm{OPh})_{10}\{\mathrm{Li}(\mathrm{thf})\}_{6}\right]$ and $\left[\{(\right.$ tmeda $\left.) \mathrm{Li}\}(\mu-\mathrm{OR})_{2}\right] \mathrm{Cr}^{29}{ }^{29}$ This latter compound finds its alkaline earth analogue in $[\{($ tmeda $) \mathrm{Li}\}(\mu-$ $\left.\mathrm{OR})_{2}\right] \mathrm{Mg}\left(\mathrm{R}=2-\mathrm{MeC}_{6} \mathrm{H}_{4} \mathrm{O}\right) .{ }^{30} \mathbf{2 6}$ and 27 correspond in their ratio
$\mathrm{LiOPh}: \mathrm{Ca}(\mathrm{OPh})_{2}$ of $6: 1$, respectively $1: 1$ to the catalytically active solution mixtures of the phenolates in the polymerization of styrene. ${ }^{31}$

With the aim of making single source precursors for oxide materials, containing several metal ions within one compound, we started to investigate multitopic ligands and their ability to coordinate to Group 11 and Group 1 or 2 metal ions. ${ }^{32-40}$ While studying Group 11 metal ions, $\mathrm{Cu}(\mathrm{I}), \mathrm{Cu}(\mathrm{II})$ and $\mathrm{Ag}(\mathrm{I})$, the problem of polymorphism and pseudo-polymorphism with such compounds became the focus of our interest. ${ }^{41-45}$

\section{Physical properties}

Among the supramolecular compounds, the calcium compound $\left.[\mathrm{Ca} \text { (diglyme })_{2}\left(\mathrm{H}_{2} \mathrm{O}\right)_{2}\right] \mathrm{I}_{2}, 9$, crystallizes in the polar space group $C c$ and possesses indeed a dipole moment perpendicular to the chain propagation direction due to the iodide anions which are all found on the same side of the cation chain. This results in the corresponding physical property of non-linear optics (NLO), the second harmonics generation (SHG) of an incoming wavelength. Similar to $\mathrm{KDP}\left(\mathrm{KH}_{2} \mathrm{PO}_{4}\right), 9$ shows this effect, however not in the same intensity. The analogue Sr-compound $\left[\mathrm{Sr}(\text { diglyme })_{2}\left(\mathrm{H}_{2} \mathrm{O}\right)_{2}\right] \mathrm{I}_{2}, \mathbf{9 a}$, does not show exactly the same structural motif. With the iodide ions being on opposite sides of the cation chain, 9a crystallises in a centro-symmetric space group, the dipole moment is extinct, and no SHG effect is observed. Whereas some molecular cluster precursors, namely 16, 17 and 18, possess dipole moments at the molecular level, the molecules are however arranged around inversion centres, thus compensating each other's dipoles.

The hydroxide-based cluster compounds $\mathbf{1 9}$ and $\mathbf{2 0}$ are charged and not volatile, but show the formation of sols upon partial hydrolysis, yielding first the hydroxides and oxides, and, upon exposure to air, the carbonates. This is an important impact in connection with biomineralisation. For CVD purposes, the cluster compounds 22, $\mathbf{2 3}$ and $\mathbf{2 4}$ are more favourable due to their neutrality and their overall hydrophobic shell which leads to weak interactions between the molecules. Thus, $\mathbf{2 4}$ was shown to be volatile. Its deposition onto $\mathrm{SrTiO}_{3}$ yielded partially crystalline material, which, after heating to $600{ }^{\circ} \mathrm{C}$ in air, transforms into halide-free particles of $\mathrm{BaO} 0.5-10 \mu \mathrm{m}$ in diameter.

Compounds 26 and 27 correspond in their chemical composition to solution mixtures of $\mathrm{LiOPh}$ and $\mathrm{Ca}(\mathrm{OPh})_{2}(6: 1$, respectively $1: 1)$, which are used in industry as catalysts in the polymerisation of styrene. ${ }^{32}$ We are therefore currently testing our compounds for such properties.

\section{Conclusions}

In our research on alkaline earth metal iodides in non-aqueous aprotic solvents, we were able to show that (Scheme 1):

i) oxygen donor ligands can act as selective scissors on 3D-solidstate compounds with different strong bond lengths to be cut.

ii) we can predict the dimensionality of supramolecular compounds based on $\left[\mathrm{M}(\mathrm{L})_{n}\left(\mathrm{H}_{2} \mathrm{O}\right)_{1-4}\right] \mathrm{I}_{2}$ via the number of water molecules coordinated to $\mathrm{M}^{2+}$.

iii) $\mathrm{MI}_{2}$ does not dissociate into solvated ions in aprotic solvents, and behaves like transition metal dihalides with formation of $\mathrm{cis}$ and trans-compounds and neutral O-donor ligands. 


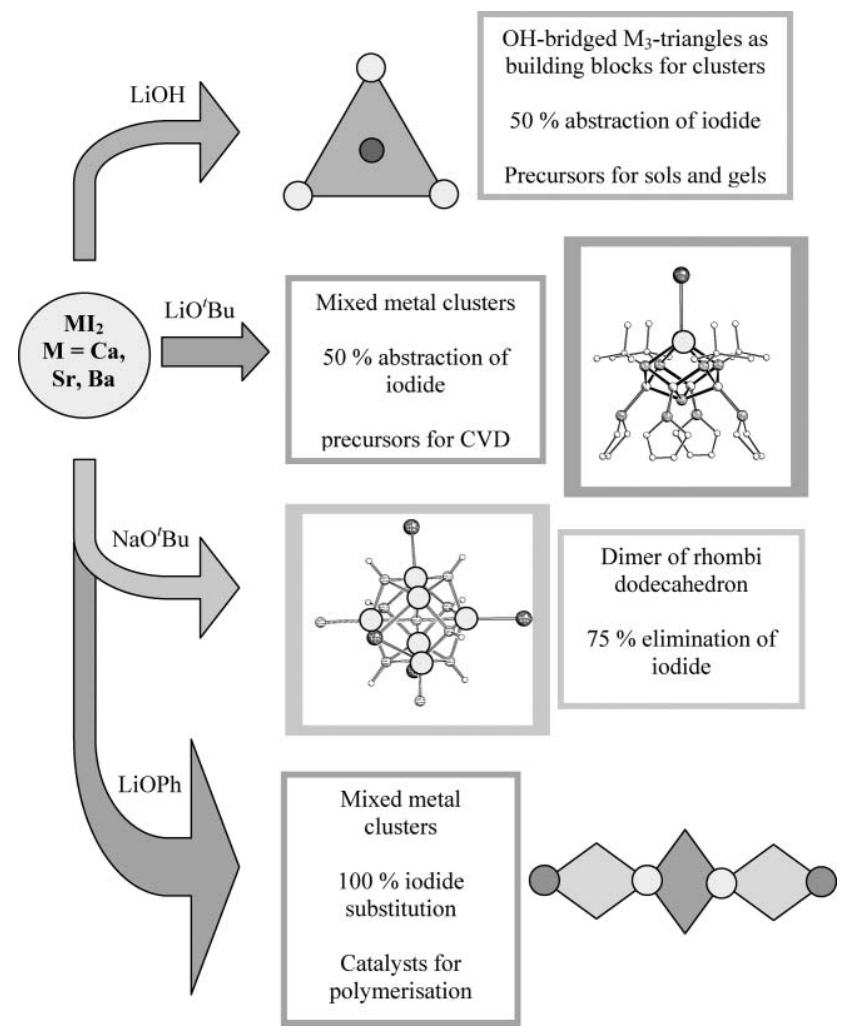

Scheme 1 Type of reactions, products and applications.

iv) Reaction with $\mathrm{LiOH}$ or $\mathrm{LiO}^{t} \mathrm{Bu}$ yields products in which $c a$. $50 \%$ of iodide has been substituted.

v) Stronger bases than $\mathrm{LiOH}$ or $\mathrm{LiO}^{t} \mathrm{Bu}$, such as $\mathrm{NaO}^{t} \mathrm{Bu}$ and LiNHPh allow the abstraction of $75 \%$ of the iodide of the initial alkaline earth metal iodide.

vi) Aryloxides allow full substitution of iodide from the initial alkaline earth metal iodide.

vii) In the last three cases, new alkaline earth metal clusters could be obtained which are constructed in a similar way to transition metal clusters.

We therefore claim that alkaline earth metal iodides behave far from purely ionically in aprotic solvents. Substitution chemistry of iodide can be carried out in a similar fashion to transition metal chemistry. Remaining iodide in the products was shown to be a versatile ligand, being able to adopt different ligating functions, from terminal binding to multiple bridging. Applications turn out to be interesting and manifold. Given these facts, a large number of new cluster and polymer coordination compounds in the field of alkaline earth metal ions can be expected. In a recent review, we have presented alkali and alkaline earth metal clusters known in the literature and their use, where an interested reader will find a good survey of the field. ${ }^{25,46}$

\section{References}

1 R. E. Mulvey, Organometallics, 2006, 25, 1060-1075 and references therein.

2 S. Harder, F. Feil and T. Repo, Chem.-Eur. J., 2002, 8, 1992-1999; D. Belli Dell'Amico, C. Bradicich, L. Labella and F. Marchetti, Inorg. Chim. Acta, 2006, 359, 1659-1665; S. Mishra, L. G. Hubert-Pfalzgraf and E. Jeanneau, Polyhedron, 2006, DOI: 10.1016/j.poly.2006.08.007.
3 K. M. Fromm, Angew. Chem., 1997, 109(24), 2876-2878, (Angew. Chem., Int. Ed. Engl., 1997, 36, 2799-2801) and references therein.

4 Katharina M. Fromm, CrystEng Comm, 2002, 4(57), 318-322.

5 K. M. Fromm and G. Bernardinelli, Z. Anorg. Allg. Chem., 2001, 627, $1626-1630$.

6 K. Boumizane, M. H. Herzog-Cance, D. J. Jones, J. L. Pascal, J. Potier and J. Roziere, Polyhedron, 1991, 10, 2757-2769.

7 A. D. Frankland, P. B. Hitchcock, M. F. Lappert and G. A. Lawless, J. Chem. Soc., Chem. Commun., 1994, 2435-2436.

8 K. M. Fromm, G. Bernardinelli, H. Goesmann, M.-J. Mayor-Lopez and J. Weber, Z. Anorg. Allg. Chem., 2000, 626, 1685-1691.

9 K. M. Fromm, G. Bernardinelli and H. Goesmann, Polyhedron, 2000, 19, 1783-1789.

10 K. M. Fromm, Chem.-Eur. J., 2001, 7, 2236-2244.

11 K. M. Fromm and H. Goesmann, Acta Crystallogr., Sect. C, 2000, 56(10), 1179-1180.

12 K. M. Fromm and W. Maudez, to be published.

13 Z. Xie, K. Chiu, B. Wu and T. C. W. Mak, Inorg. Chem., 1996, 35(20), 5957-5958; W. J. Evans, T. S. Gummersheimer and J. W. Ziller, J. Am. Chem. Soc., 1995, 117(35), 8999-9002; G. Heckmann and M. Niemeyer, J. Am. Chem. Soc., 2000, 122(17), 4227-4228; L. Huebner, A. Kornienko, T. J. Emge and J. G. Brennan, Inorg. Chem., 2004, 43(18), 5659-5664; M. Niemeyer, Acta Crystallogr., Sect. E, 2001, 57(8), m363$\mathrm{m} 364$.

14 K. M. Fromm, E. D. Gueneau, G. Bernardinelli, H. Goesmann, J. Weber, M.-J. Mayor-López, P. Boulet and H. Chermette, J. Am. Chem. Soc., 2003, 125(12), 3593-3604 and references therein.

15 K. F. Tesh, D. J. Burkey and T. P. Hanusa, J. Am. Chem. Soc., 1994, 116(6), 2409-2417.

16 K. M. Fromm, Chimia, 2003, 57(4), 175-178.

17 K. M. Fromm, CrystEng Comm, 2002, 4(57), 318-322.

18 K. M. Fromm and W. Maudez, Eur. J. Inorg. Chem., 2003, 18, 34403444.

19 R. J. Gillespie and E. A. Robinson, Angew. Chem., 1996, 108, 539-560, (Angew. Chem., Int. Ed. Engl., 1996, 35, 495-514).

20 E. D. Brady, T. P. Hanusa, M. Pink and V. G. Young, Jr., Inorg. Chem., 2000, 39, 6028-6037.

21 K. M. Fromm, Chem. Commun., 1999, 17, 1659-1660.

22 K. M. Fromm, E. D. Gueneau, A. Y. Robin, W. Maudez, J. Sague and R. Bergougnant, Z. Anorg. Allg. Chem., 2005, 631, 1725-1740.

23 R. D. Thomas, S. G. Bott, P. W. Gravelle and H. D. Nguyen, Book of Abstracts, 215th ACS National Meeting, Dallas, March $29^{\text {th }}$-April $2^{\text {nd }}$, 1998.

24 K. M. Fromm, E. D. Gueneau and H. Goesmann, Chem. Commun., 2000, 2187-2188.

25 K. M. Fromm and E. D. Gueneau, Polyhedron, 2004, 23(9), 1479-1504.

26 W. Maudez, T. Vig-Slenters, L. Mirolo, A. Fleury and K. M. Fromm, Main Group Met., 2006, DOI: 10.1080/10241220600841862.

27 A. R. Kennedy, J. G. MacLellan, R. E. Mulvey and A. Robertson, J. Chem. Soc., Dalton Trans., 2000, 22, 4112-4116.

28 W. Maudez, D. Häussinger and K. M. Fromm, Z. Anorg. Allg. Chem., 2006, DOI: 10.1002/zaac.200600170.

29 J. J. H. Edema, A. Meetsma, S. Gambarotta, J. S. I. Khan, W. J. J. Smeets and A. L. Spek, Inorg. Chem., 1991, 30, 3639-3646.

30 K. W. Henderson, R. E. Mulvey and F. B. M. Reinhard, J. Am. Chem. Soc., 1994, 116, 10777-10778.

31 A. F. Halasa, W.-L. Hsu and J. R. Zuppo, U.S. Pat. Appl., 20050181935, 2005.

32 K. M. Fromm, E. D. Gueneau, J.-P. Rivera, G. Bernardinelli and H. Goesmann, Z. Anorg. Allg. Chem., 2002, 628, 171-178.

33 K. M. Fromm, E. D. Gueneau, H. Goesmann and C. Bochet, Z. Anorg. Allg. Chem., 2003, 629(4), 597-600.

34 M. Dulak, R. Bergougnant, K. M. Fromm, H. R. Hagemann, A. Y. Robin and T. A. Wesolowski, Spectrochim. Acta, Part A, 2005, 64, $532-548$.

35 K. M. Fromm, R. D. Bergougnant and A. Y. Robin, Z. Anorg. Allg. Chem., 2006, 632, 828-836.

36 M. G. Zolotukhin, G. Hernández, M. del Carmen, A. M. Lopez, L. Fomine, G. Cedillo, A. Nogales, T. Ezquerra, D. Rueda, H. M. Colquhoun, K. M. Fromm, A. Ruiz-Treviño and M. Ree, Macromolecules, 2006, 39, 4696-4703.

37 R. D. Bergougnant, A. Y. Robin and K. M. Fromm, Cryst. Growth Des., 2005, 5(5), 1691-1694.

38 K. M. Fromm, E. D. Gueneau, H. Goesmann and C. Bochet, Z. Anorg. Allg. Chem., 2003, 629(4), 597-600. 
39 E. D. Gueneau, K. M. Fromm and H. Goesmann, Chem.-Eur. J., 2003, 9(2), 509-514.

40 K. M. Fromm, E. D. Gueneau, J.-P. Rivera, G. Bernardinelli and H. Goesmann, Z. Anorg. Allg. Chem., 2002, 628, 171-178.

41 A. Y. Robin, K. M. Fromm, H. Goesmann and G. Bernardinelli, CrystEngComm, 2003, 5(71), 405-410.

42 J. L. Sagué Doimeadios, A. Y. Robin and K. M. Fromm, Chem. Commun., 2005, 36, 4548-4550.
43 A. Y. Robin, J. L. Sagué and K. M. Fromm, CrystEngComm, 2006, 8, 403-416.

44 J. L. Sague and K. M. Fromm, Cryst. Growth Des., 2006, 6(7), 15661568.

45 K. M. Fromm, Kirk-Othmer Encyclopedia of Chemical Technology, John Wiley \& Sons, Inc., Hoboken, 2003.

46 A. Y. Robin and K. M. Fromm, Coord. Chem. Rev., 2006, 250, $2127-$ 2157. 